\title{
CX.-The Solvent Properties of Mixed Liquids in Relation to the Chemical Characters and Solvent Properties of their Components.
}

By Harry Medforth Dawson.

THE solvent power of mixed liquids in relation to that of the components has been a frequent subject of investigation. Bruner (Zeit. physikal. Chem., 1898, 26, 145) has given a list of these investigations. In nearly all cases, the solvents used have been mixtures of ethyl alcohol and water, in which the solubilities of various solid substances have been investigated. The solid substances employed in the earlier determinations were electrolytes (salts), non-electrolytes having only been used by Holleman and Autusch (Rec. Trav. Chim., 1894, 13, 277). The investigation of the solubility of electrolytes with the view of drawing general conclusions is not quite satisfactory, since the degree of electrolytic dissociation will vary with the concentration of the dissolved substance and the composition of the liquid mixture. Any existing simple relationships will thus be unnecessarily complicated. Bruner (loc. cit.) determined the solubility of iodine in mixed liquids, the solvents employed being benzene, carbon disulphide, chloroform, carbon tetrachloride, ethyl alcohol, and $n$-propyl alcohol, these were chosen with the view of having the experimental conditions as simple as possible, the formation of molecular compounds between solute and solvent or between two solvents being in these cases very improbable. The results obtained by Bruner show that the solubility of iodine in a mixture of two liquids is always smaller than it should be according to the simple rule of mixtures, a result agreeing with the previous observations on alcohol-water mixtures. 
On account of the very considerable concentration of some of the saturated iodine solutions, it is probable, however, that the experimental conditions chosen by Bruner are not suitable for investigating the dependence of the solvent power of mixtures on the character and relative proportions of the components. The molecular condition of the dissolved iodine is probably not the same in each of the saturated solutions, in which case the results obtained will not be of the simplest possible character. In the case of solutions of iodine in carbon disulphide, it has been shown by Jakowkin (Zeit. physikal. Chem., 1895, 18, 585 ) that with increasing concentration the iodine forms molecules of greater complexity than those which are present in the more dilute solutions. This shows itself in a gradually increasing value of the distribution-coefficient for the system carbon disulphide-water with increasing iodine concentration. It may be inferred from this that if the solution of a third substance in a liquid mixture is to serve as a means of investigating the character of such composite liquids, the concentration of the dissolved substance should be small. Moreover, the concentrations attained in some of Bruner's experiments are so large that the simple laws which hold good for dilute solutions are not even approximately satisfied. Determinations of the solubility of gases in liquid mixtures offer, no doubt, very suitable conditions for the investigation of the problem, but only few experiments have been carried out in this direction. The solubility of carbon dioxide and of hydrogen, oxygen, and carbon monoxide in mixtures of ethyl alcohol and water has been investigated by Miiller (Ann. Phys. Chem., 1889, [iii], 37, 24) and by Lubarsch (ibid., 524), and Just (Zeit. physikal. Chem., 1901, 37, 342) determined the solubility of the first gas in several different mixtures of organic liquids.

The experimental work involved in the determination of the solubility of gases is, however, not nearly so simple as when solid substances are under investigation. Instead of carrying out solubility determinations of gases in liquids, the ratio of distribution of substances between practically non-miscible liquids may be investigated. The laws regulating this distribution are well known to be of the same simple character as those which regulate the absorption of gases by liquids. If one of these liquids, for example, water, is taken as standard, then various organic liquids, or mixtures of these in different proportions, may be taken as the second non-miscible medium. The third substance may then be added in such quantity to the two liquids that the resulting solutions are comparatively dilute, whereby the complications introduced by dealing with concentrated solutions are avoided.

In this paper, the author has investigated the distribution of iodine 
between liquids composed of organic solvents in different proportions on the one hand, and water on the other, the organic solvents employed being carbon disulphide, benzene, toluene, chloroform, carbon tetrachloride, and light petroleum. ${ }^{*}$ Two difficulties present themselves in connection with the accurate determination of the ratio in which iodine distributes itself between water and organic solvents such as have been used in this investigation, the first of these being caused by the great disparity between the concentrations in the two solvents, and the second by the very small concentration of iodine in the water layer when the other solutions are sufficiently dilute. If the two liquids do not separate completely from each other on standing so that traces of the one remain suspended in the other, the enormous difference of the two iodine concentrations will give rise to considerable errors, in addition to which the small quantity and volatility of the iodine in the water layer make an accurate determination of its concentration somewhat uncertain. These sources of error have been avoided by the use of a solution of potassium iodide instead of pure water. It has been shown (Jakowkin, Zeit. physikal. Chem., 1896, 20, 19 ; Dawson, Trans., 1901, 79, 238) that the formation of potassium tri-iodide takes place in a solution containing iodine and potassium iodide, and that the components of the solution are in equilibrium with one another as represented by the equation

$$
\mathrm{KI}+\mathrm{I}_{2} \rightleftarrows \mathrm{KI}_{3} \text {. }
$$

If one gram-molecule of iodine (as measured by titration with sodium thiosulphate) is contained in $v$ litres, and $x$ is the fraction of this iodine which is uncombined, and if further $a$ molecules of potassium iodide are contained in volume $v$, then $\frac{a-1+x}{v}, x$ and $\frac{1-x}{v}$ represent respectively the concentrations of potassium iodide, free iodine, and potassium tri-iodide. Applying the law of mass action to the dissociation equilibrium, we obtain for the equilibrium constant :

$$
K=\frac{(a-1+x) x}{v(1-x)}
$$

Experiments have shown that if the solutions are not too concentrated the value of $K$ remains constant.

It is obvious that if the value of the constant $K$ is known accurately for a given temperature, the above equation will enable us to calculate

* The experiments described were carried out two years ago, publication having been deferred by reason of the author's desire to extend the observations. This has not been possible, and the results obtained are now communicated. 
the value of $x$ if $a$ and $v$ are known. In other words, it is possible to calculate the concentration of the free iodine in any solution of iodine in potassium iodide if the concentrations of the total iodine and the potassium iodide are known. Since it is only the uncombined iodine in the aqueous solution which determines directly the resultant state of equilibrium between the iodine dissolved in the two nonmiscible liquids, this calculation will give the factor which is to be used for the aqueous solution in the deduction of the value of the distribution-coefficient.

In order to determine the value of $\boldsymbol{K}$ for the iodine-potassium iodide solution for the temperature $15^{\circ}$, at which all the experiments were carried out, preliminary measurements of the ratio of the distribution of iodine between pure water and some one non-miscible solvent were necessary. Carbon disulphide was chosen, this solvent having already been used at higher temperatures by Berthelot and Jungfleisch and by Jakowkin. Conductivity water was used in the experiments, and the carbon disulphide employed was distilled successively over lime, mercury, corrosive sublimate, and copper, its odour after this treatment being decidedly ethereal. Thirty c.c. of carbon disulphide, 300 c.c. of water, and a quantity of resublimed iodine vere introduced into a stoppered separating funnel and the latter immersed in a thermostat at $15^{\circ}$. After repeated shaking of the contents of the funnel, the latter was allowed to stand for an hour in the thermostat. The two layers were then separated, and the concentration of the iodine in each determined. The following numbers, representing grams per litre, were obtained in three experiments, the values of the distribution-coefficient being appended in the third column :

\begin{tabular}{|c|c|c|}
\hline Concentration in water. & $\begin{array}{c}\text { Concentration in } \mathrm{CS}_{2} \text {. } \\
c^{\prime} \text {. }\end{array}$ & $\begin{array}{c}\text { Distribution } \\
\text { coefficient. } \\
c^{\prime} / c .\end{array}$ \\
\hline $0 \cdot 04516$ & $27 \cdot 85$ & $616 \cdot 8$ \\
\hline $0 \cdot 04856$ & 30.09 & $619 \cdot 6$ \\
\hline \multirow[t]{2}{*}{0.04857} & $30 \cdot 31$ & $624 \cdot 0$ \\
\hline & & 620 \\
\hline
\end{tabular}

This mean value of the distribution-coefficient has been used for the calculation of the equilibrium constant $K$ at $15^{\circ}$. Approximately equal volumes of carbon disulphide and $N / 10$ potassium iodide were shaken together after addition of a small quantity of iodine, and the iodine concentration in the two layers determined as before. In the following table, $c$ is the iodine concentration in the aqueous layer in grams per litre, $c^{\prime}$ that in the carbon disulphide, and $v$ the volume (in litres) of aqueous solution containing one gram-molecule 
of iodine. The concentration of the uncombined iodine in the aqueous solution $c x$ is obviously equal to $\frac{c^{\prime}}{620}$, and the degree of dissociation $x$ to $\frac{c^{\prime}}{620 c}$, if it is assumed that the dissolved potassium iodide has no influence (apart from the purely chemical action) on the iodine distribution, and this is very approximately the case since the solution is only one-tenth normal in regard to potassium iodide. The following numbers were obtained in two experiments :

\begin{tabular}{|c|c|c|c|c|c|}
\hline $\begin{array}{c}c \cdot \\
2 \cdot 154\end{array}$ & $\begin{array}{c}c^{\prime} . \\
14 \cdot 89\end{array}$ & $\begin{array}{c}v . \\
117 \cdot 8\end{array}$ & $\begin{array}{c}c x . \\
0.02402\end{array}$ & $\begin{array}{c}x . \\
0.01115\end{array}$ & $\begin{array}{c}K . \\
0.001033\end{array}$ \\
\hline $3 \cdot 832$ & $28 \cdot 65$ & $66 \cdot 2$ & $0 \cdot 04621$ & 0.01206 & 0.001038 \\
\hline & & & & Mea & 0.001035 \\
\hline
\end{tabular}

The value of the equilibrium constant having been determined in this manner, the concentration of the uncombined iodine in any aqueous solution can be calculated.

In all the experiments, the concentration of the potassium iodide solution was one tenth normal, and, except in one case, the concentration of the iodine in the aqueous solution was contained between the limits of 2.154 and 3.832 grams per litre, which were the concentrations used in the above experiments for determining the value of $K$.

It may be noted that the value of $x$ is very small in comparison with $(a-1)$, and in consequence equation (1) may be written in the simpler form

$$
x=\frac{K v}{a+K v-1} .
$$

The concentration of the uncombined iodine in the aqueous solution is therefore given by

or since

$$
c x=\frac{c K v}{a+K v-1}
$$

$$
\begin{gathered}
K=0.001035, c v=253 \cdot 7, \text { and } a=\frac{v}{10} \\
c x=\frac{0.2625}{0 \cdot 1010 v-1} \quad \text { (2). }
\end{gathered}
$$

By means of this last equation the concentration of the uncombined iodine in the aqueous solution can be at once calculated from the concentration $\left(\frac{1}{v}\right)$ of the total iodine as measured by titration with sodium thiosulphate. The corresponding concentration in the organic solvent $c^{\prime}$ having been determined, the ratio of distribution 
of the iodine is given by $k=\frac{c^{\prime}}{c x}$. If in the different experiments the value of $c x$ remains constant, the experimental conditions are practically the same as when the solubility of a gas under constant pressure is investigated.

Mixtures of benzene and carbon disulphide were first subjected to investigation, and the values of the distribution-coefficient for the simple liquids alone having been determined, the coefficients for liquids containing the components in different proportions were measured. Thirty c.c. of $N / 10$ potassium iodide solution and 25 c.c. of benzene were shaken together after addition of a certain quantity of iodine. In a second experiment, 20 c.c. of benzene and 5 c.c. of carbon disulphide were employed; in a third, 15 c.c. of benzene and 10 c.c. of carbon disulphide, and so on. In all the experiments, the same volume of potassium iodide solution, and, except in a few cases, the volume of the organic solvent, was 25 c.c. Since the capacity of the vessel was only about 60 c.c., very little space was available for vaporisation, and even in the case of the most volatile liquid used change of volume from this cause could be entirely neglected.

In the following tables, the first column contains numbers representing the composition of the liquid mixture employed; these numbers express the percentage volume of the one liquid in terms of the sum of the volumes (before mixing) of the two liquids which form the mixture. The small changes of volume which take place on mixing have therefore been neglected. No account, moreover, has been taken of the changes in volume resulting from the mutual solubility of water and the organic solvents. In all the cases investigated, the reciprocal solubility is so small, however, that errors in the estimation of the composition of the liquid mixture arising from this cause are probably negligible. The letters $c, c^{\prime}, c x$, and $k$ in the next four columns have the significance already ascribed to them. Under $k^{\prime}$, the value of the distribution-coefficient for the liquid mixture, as calculated from the coefficients for the simple liquids according to the simple law of mixtures, is given. If $k_{a}$ and $k_{b}$ denote the distribution-coefficients for the component liquids, and if the mixture contains a volumes per cent. of the solvent for which the coefficient is $k_{a}$, then $k^{\prime}$ is obtained from the formula

$$
k^{\prime}=\frac{a k_{a}+(100-a) k_{b}}{100} \text {. }
$$

In the last column, the percentage difference between the values of $k$ and $k^{\prime}$ is given. 


\section{DAWSON : THE SOLVENT PROPERTIES OF MIXED LIQUIDS.}

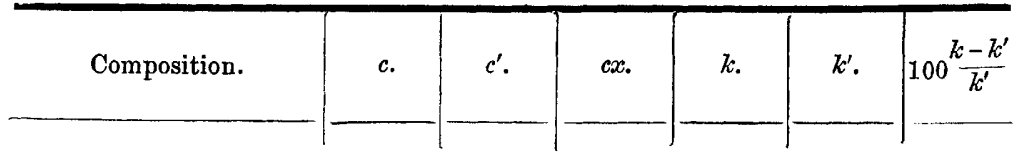

Benzene and carbon disulphide.

\begin{tabular}{|c|c|c|c|c|c|c|c|c|c|}
\hline \multirow{2}{*}{\multicolumn{4}{|c|}{100 per cent. benzene ... }} & $3 \cdot 819$ & $18 \cdot 38$ & 0.04598 & $399 \cdot 9$ & - & \\
\hline & & & $\ldots$ & $3 \cdot 134$ & $14 \cdot 62$ & 0.03658 & $399 \cdot 8$ & 一 & - \\
\hline $86 \cdot 2$ & ," & $"$ & $\ldots$ & $3 \cdot 061$ & $15 \cdot 90$ & 0.03559 & $446 \cdot 6$ & $430 \cdot 1$ & $+3 \cdot 8$ \\
\hline 60 & $"$ & ", & $\ldots$ & $2 \cdot 968$ & $17 \cdot 76$ & 0.0336 & $528 \cdot 5$ & $487 \cdot 9$ & $8 \cdot 3$ \\
\hline 50 & ," & ," & . & $3 \cdot 115$ & $20 \cdot 02$ & 0.03633 & $551 \cdot 1$ & $509 \cdot 9$ & $8 \cdot 1$ \\
\hline$\{40$ & ," & ," & $\ldots$ & $2 \cdot 995$ & $19 \cdot 78$ & 0.03475 & $569 \cdot 3$ & $531 \cdot 9$ & $7 \cdot 0$ \\
\hline 140 & ," & ", & $\cdots$ & $3 \cdot 134$ & $20 \cdot 80$ & 0.03658 & $568 \cdot 5$ & $531 \cdot 9$ & $6 \cdot 9$ \\
\hline$\{20$ & ", & ", & $\cdots$ & $2 \cdot 957$ & $20 \cdot 69$ & 0.03425 & $604 \cdot 3$ & $576 \cdot 0$ & $4 \cdot 9$ \\
\hline 120 & , & ", & $\cdots$ & $2 \cdot 925$ & $20 \cdot 41$ & 0.03382 & $603 \cdot 6$ & $576 \cdot 0$ & $4 \cdot 8$ \\
\hline & ", & ," & & - & - & - & $620 \cdot 0$ & & \\
\hline
\end{tabular}

Toluene and carbon disulphide.

\begin{tabular}{|c|c|c|c|c|c|c|c|c|c|}
\hline${ \hline \multirow { 2 } { * }\multicolumn{4}{|c|}{\begin{array}{l}100 \text { per cent. toluene } \\
100\end{array}}}$ & $2 \cdot 887$ & $15 \cdot 38$ & 0.03332 & $461 \cdot 7$ & 一 & \\
\hline & & & ... & $2 \cdot 925$ & $15 \cdot 55$ & 0.03382 & 460.9 & - & - \\
\hline 60 & ", & $"$ & $\cdots$ & $2 \cdot 957$ & $19 \cdot 04$ & 0.03425 & $556^{\circ} 0$ & $524 \cdot 8$ & $+5 \cdot 9$ \\
\hline$\{40$ & ," & ", & $\cdots$ & $2 \cdot 854$ & $19 \cdot 44$ & 0.03921 & $590 \cdot 9$ & $556 \cdot 5$ & $6 \cdot 2$ \\
\hline 140 & " & ," & & $2 \cdot 906$ & $19 \cdot 89$ & 0.03357 & $591 \cdot 6$ & $556 \cdot 5$ & $6 \cdot 3$ \\
\hline$\left\{\begin{array}{l}20 \\
20\end{array}\right.$ & ", & ," & $\cdots$ & $2 \cdot 786$ & $19 \cdot 90$ & 0.03202 & $621 \cdot 5$ & $588 \cdot 3$ & $5 \cdot 6$ \\
\hline 120 & ", & ", & & $2 \cdot 890$ & $20 \cdot 56$ & 0.03336 & $616 \cdot 2$ & $588 \cdot 3$ & $4 \cdot 7$ \\
\hline & ", & ", & & & - & - & 0200 & - & \\
\hline
\end{tabular}

Benzene and toluene.

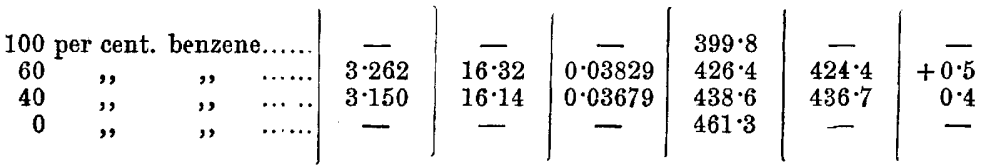

Benzene and light petroleum. (B. p. $83-85^{\circ}$ ).

\begin{tabular}{|c|c|c|c|c|c|c|c|c|c|}
\hline \multicolumn{4}{|c|}{100 per cent. benzene...... } & - & - & - & $399 \cdot 8$ & - & \\
\hline 80 & ", & ," & ....... & $3 \cdot 352$ & $12 \cdot 02$ & 0.03953 & $304 \cdot 2$ & $326 \cdot 4$ & $-6 \cdot 8$ \\
\hline 60 & ", & ", & ....... & $3 \cdot 890$ & $9 \cdot 970$ & 0.04697 & $212 \cdot 2$ & $253 \cdot 1$ & $16 \cdot 1$ \\
\hline 40 & ", & ", & ..... & $3 \cdot 239$ & $5 \cdot 262$ & 0.03799 & $138 \cdot 6$ & $179 \cdot 6$ & $22 \cdot 8$ \\
\hline 20 & , & ," & ...... & $3 \cdot 166$ & $2 \cdot 876$ & 0.03700 & $77 \cdot 7$ & $106 \cdot 3$ & $26 \cdot 9$ \\
\hline 0 & ," & ," & & $4: 593$ & 1.886 & 0.05731 & $32 \cdot 9$ & - & - \\
\hline
\end{tabular}

Carbon disulphide and light petroleum. (B. p. $83-85^{\circ}$ ).

\begin{tabular}{|c|c|c|c|c|c|c|c|c|c|}
\hline \multicolumn{3}{|c|}{100 per cent. $\mathrm{CS}_{2}$} & & - & 一 & - & 620 & - & \\
\hline 80 & " &, & ........... & 3.089 & $14 \cdot 93$ & 0.03597 & $415 \cdot 1$ & $502 \cdot 6$ & $-17 \cdot 4$ \\
\hline 60 & ," & ," & .......... & $3 \cdot 406$ & 10.58 & 0.04024 & $262 \cdot 8$ & $385 \cdot 2$ & $31 \cdot 8$ \\
\hline 40 & ," & ,", & ........... & $3 \cdot 310$ & $5 \cdot 846$ & 0.03892 & $150 \cdot 2$ & $267 \cdot 7$ & $43 \cdot 9$ \\
\hline 20 & , & ", & .......... & $3 \cdot 491$ & $3 \cdot 335$ & 0.04142 & $78 \cdot 1$ & $150 \cdot 3$ & $48 \cdot 0$ \\
\hline 0 & , & ", & .......... & - & - & - & $32 \cdot 9$ & - & - \\
\hline
\end{tabular}


DAWSON : THE SOLVENT PROPERTIES OF MIXED LIQUIDS. 1093

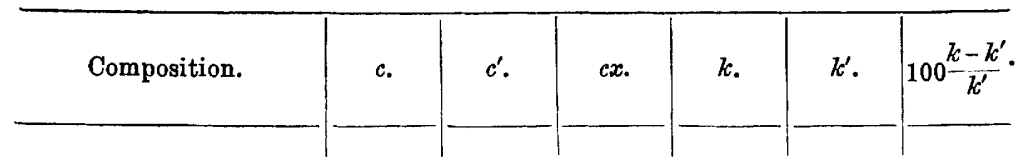

Carbon disulphide and chloroform.

\begin{tabular}{|c|c|c|c|c|c|c|c|c|c|}
\hline & 100 per cent. $\mathrm{CHCl}_{3} \ldots \ldots$ & - & - & 一 & $120 \cdot 7$ & - & \\
\hline 80 & ", & $"$ & ...... & $3 \cdot 471$ & $7 \cdot 711$ & 0.04112 & $187 \cdot 5$ & $220 \cdot 6$ & $-15^{\circ} 0$ \\
\hline 60 & , & ", & ...... & $3 \cdot 378$ & $10 \cdot 99$ & 0.03986 & $275 \cdot 8$ & $320 \cdot 4$ & $15 \cdot 9$ \\
\hline 50 & , & ," & ....... & $3 \cdot 414$ & $13 \cdot 11$ & 0.04033 & $324 \cdot 9$ & $370 \cdot 3$ & $12 \cdot 3$ \\
\hline 40 & ", & ", & ....... & 3.051 & $13 \cdot 56$ & 0.03547 & $382 \cdot 3$ & $420 \cdot 3$ & $9 \cdot 0$ \\
\hline 20 & ," & ," & ...... & $3 \cdot 265$ & $19 \cdot 14$ & 0.03832 & $499 \cdot 6$ & $520 \cdot 1$ & $3 \cdot 9$ \\
\hline 0 & " & $"$ & ...... & - & - & - & $620^{\circ} 0$ & 一 & - \\
\hline
\end{tabular}

Chloroform and benzene.

\begin{tabular}{|c|c|c|c|c|c|c|c|c|c|}
\hline \multicolumn{3}{|c|}{100 per cent. $\mathrm{CHCl}_{3}$} & ....... & - & - & - & $120 \cdot 7$ & 一 & - \\
\hline 80 & $"$ &, & ....... & $3 \cdot 141$ & $5 \cdot 640$ & 0.03666 & 153.8 & 176.5 & $-12 \cdot 9$ \\
\hline 60 & $"$ & ", & ....... & $3 \cdot 599$ & $8 \cdot 231$ & 0.04289 & $191 \cdot 9$ & $232 \cdot 3$ & $17 \cdot 4$ \\
\hline 50 & ," & ", & ....... & $3 \cdot 246$ & $8 \cdot 356$ & 0.03808 & $219 \cdot 5$ & $260 \cdot 2$ & $15 \cdot 6$ \\
\hline 40 & ," & ", & ....... & $3 \cdot 150$ & $9 \cdot 230$ & 0.03679 & 250.9 & $288 \cdot 2$ & $12 \cdot 9$ \\
\hline 0 & ," & ", & ...... & - & - & - & $399 \cdot 8$ & - & - \\
\hline
\end{tabular}

Carbon tetrachloride and carbon disulphide.

\begin{tabular}{|c|c|c|c|c|c|c|c|c|c|}
\hline \multirow{2}{*}{\multicolumn{4}{|c|}{${ }_{80} 00$ per cent. $\mathrm{CCl}_{4} \ldots \ldots \ldots}}$. & $3 \cdot 681$ & $3 \cdot 631$ & 0.04404 & $82 \cdot 4$ & - & \\
\hline & & & & $3 \cdot 070$ & $4 \cdot 949$ & 0.03573 & $138 \cdot 6$ & $189 \cdot 9$ & -27 \\
\hline 60 & , & ", & ........... & $3 \cdot 210$ & $8 \cdot 305$ & 0.03758 & $221 \cdot 0$ & $297 \cdot 4$ & \\
\hline 40 & ", & ", & & $2 \cdot 817$ & 10.58 & 0.03243 & $326 \cdot 3$ & $404 \cdot 9$ & $19 \cdot 4$ \\
\hline 25 & ," & ", & ........... & $3 \cdot 378$ & $17 \cdot 08$ & 0.03985 & $428 \cdot 6$ & $485 \cdot 6$ & $11 \cdot 7$ \\
\hline 0 & ," & ", & .... & - & - & - & $620^{\circ} 0$ & - & - \\
\hline
\end{tabular}

Carbon tetrachloride and toluene.

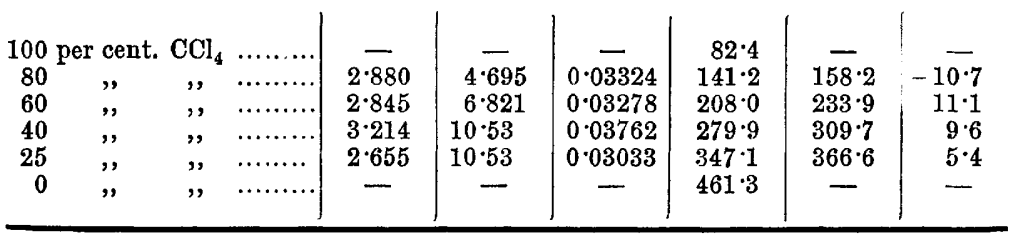

The organic solvents employed in the above experiments were purified by distillation. The light petroleum was obtained by repeated distillation of a large volume of light petroleum, the fraction used distilling between $83^{\circ}$ and $85^{\circ}$. Its employment arose from a desire to ascertain the behaviour of a fatty hydrocarbon towards an aromatic hydrocarbon, and although not consisting of a definite chemical compound, the results obtained agree probably very closely with those which would have been observed if pure heptane had been used.

It may be noticed that the concentrations of the iodine in the organic 
solvents in no case exceeded 20 grams per litre, so that only dilute solutions have been under investigation. The concentration of the free uncombined iodine in the aqueous solution is always less than 0.05 gram per litre, and, with one exception, the concentrations lie between 0.033 and 0.046 gram per litre, so that the concentration of the iodine in the aqueous layer is practically constant.

In the case of most of the liquid mixtures investigated, the observed value of the distribution coefficient $(k)$ is less than the value $\left(k^{\prime}\right)$, calculated from the mixture rule; in other words, the proportion of iodine in the mixture relative to that in water is less than that calculated on the basis of the rule of mixtures from the relative proportions in the simple solvents under similar conditions. This result obviously corresponds to the results generally obtained in previous experiments on the solubility of substances in liquid mixtures. For mixtures of carbon disulphide and benzene, and of carbon disulphide and toluene, on the other hand, a higher value is found experimentally for the distribution coefficient than that calculated in the above described manner. Finally, for mixtures of benzene and toluene, the observed and calculated values of the distribution-coefficient agree within the limits of experimental error. In this case, the two components of the mixture exert an influence on the property under investigation the magnitude of which can be estimated from the behaviour of the two liquids when investigated separately. On account of the comparatively small difference between the distribution-coefficient for benzene and toluene, it is not possible, however, to determine very accurately to what extent the two liquids exert no influence on each other. The different behaviour of mixtures of carbon disulphide and benzene, and of carbon disulphide and toluene, as compared with the other mixtures investigated, is noteworthy, for here we meet with relationships which have not been previously observed, except in Just's preliminary experiments (loc. cit.) on the solubility of carbon dioxide in mixtures of benzene and benzyl chloride, and of nitrobenzene and amyl alcohol.

The percentage difference between $k$ and $k^{\prime}$ for these two liquid mixtures is, bowever, comparatively small, and at corresponding concentrations is practically the same in the two cases. Much greater differences between the observed and calculated values of the distribution-coefficient are exhibited by the remaining mixtures where $k^{\prime}$ is greater than $k$, a difference of nearly 50 per cent. being found in the case of a mixture of carbon disulphide and light petroleum.

Inspection of the tables shows further that the maximum percentage difference between the values of $k$ and $k^{\prime}$ does not in general correspond to a mixture containing equal volumes of the components, but to a mixture containing considerable excess of the liquid with the smaller distribution-coefficient. This is very clearly seen in the case of a mix- 
ture of carbon disulphide and chloroform, where the maximum deviation corresponds to the mixture of chloroform 80 per cent., and carbon disulphide 20 per cent. In other words, the deviations from the simple mixture rule are greater when a small quantity of liquid with a high solvent power is added to a considerable quantity of a liquid with a small solvent power, than when a liquid of small solvent power is added in small quantity to a considerable volume of a liquid of high solvent power. In the case of two liquids with approximately equal solvent powers, this maximum deviation is to be found in mixtures containing the components in approximately equal proportions by volume.

In the accompanying diagram, the distribution-coefficient $k$, which measures the solvent power of the organic solvent, is plotted as a function of the composition of the mixture. The percentage by volume of the components is marked off on the abscissa, and the ordinate represents the distribution-coefficient. A series of continuous curves is thus obtained. For mixtures of carbon disulphide and benzene or toluene the curve is above the straight line joining the end points, for benzene and toluene the experimental curve and straight line are practically coincident, and for the other mixtures the curve lies below the line. The values of $k^{\prime}$ given in the tables are obviously represented by points on the straight lines joining the end points of the curves. In no case do the above curves exhibit maxima or minima.

Minimum solubilities in the case of mixtures of ethyl alcohol and water have, however, been observed for hydrogen, oxygen, carbon monoxide, and carbon dioxide (Müller, Lubarsch, loc. cit.), each of these gases being least soluble in a mixture containing about 28 per cent. alcohol. It is, however, probable that interaction between the components takes place in this case. Nearly all the properties of alcoholwater mixtures give evidence of this. Dilute alcohol of the above composition is also characteristic in regard to the specific heat, the heat development on mixing the components, and the surface tension, all these properties showing maximum deviation from the values calculated on the basis of the rule of mixtures at approximately this concentration. The supposition is further confirmed by the freezing point measurements of Mihály (Zeit. physikal. Chem., 1897, 24, 13) who observed that addition of small quantities of water to benzene containing dissolved alcohol raises the freezing point of the henzene solution.

It seems possible that maximum or minimum solvent powers may be conditioned by some interaction of the components whereby new molecular complexes are formed. If the formation of complex molecules from the components does not take place, and this is improbable in the case of the liquid mixtures in vestigated in this paper, then such maxima or minima are scarcely to be expected.

The results obtained in this paper indicate that the solvent power 
1096 DAWSON : THE SOLVENT PROPER'TIES OF MIXED LIQUIDS.

Ratio of disiribution of iodine between water and binary organic liquid mixtures.

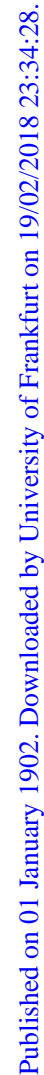

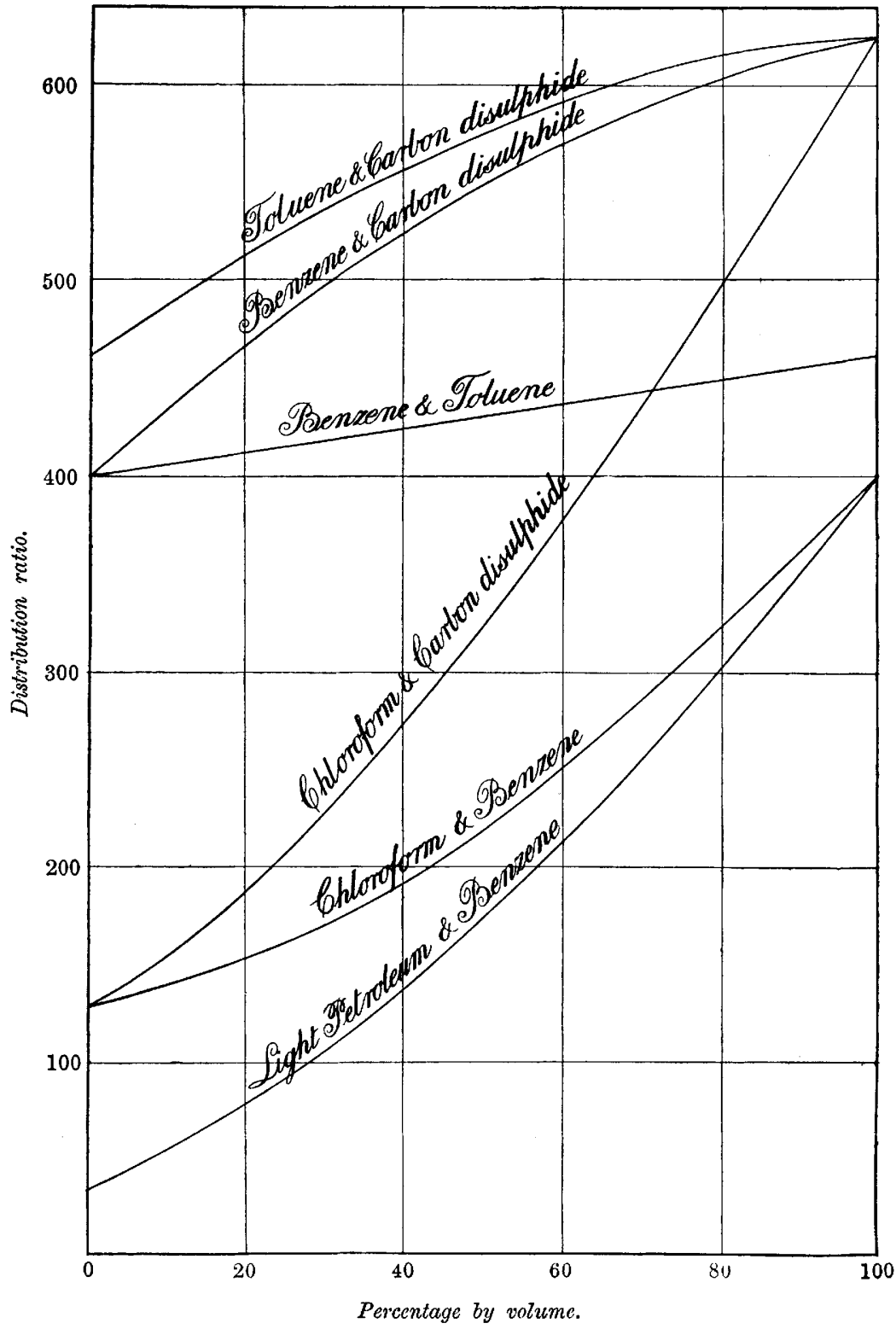


of mixed liquids, the components of which are probably without any action on each other, is generally smaller than the sum of the solvent powers of the two components when taken in the quantities in which they are present in the mixture. In some cases, however, the solvent power of mixtures has been found equal to or greater than that of the components separately.

\section{Addendum.}

Since this paper was communicated to the Society, the results of an investigation of the solubility of carbon monoxide in binary organic mixtures by F. W. Skirrow have appeared in the Zeitschrift für physikalische Chemie (1902, 41, 139).

Whilst for the great majority of liquid pairs investigated the solvent power of the mixture is less than that corresponding to the simple mixture rule, yet, as in the above investigation, exceptions to this have been observed. Moreover, several instances of mixtures have been met with which have a greater solvent power than either of the components, and it is shown that, in some cases at any rate, such pairs of liquids exhibit a minimum value of the surface-tension. The maxima and minima do not appear, however, to correspond to mixtures of the same percentage composition, and it is quite possible that both phenomena are due to one and the same cause-the formation of new molecular complexes in the liquid mixture.

The Yorkshire College, LEEDS. 